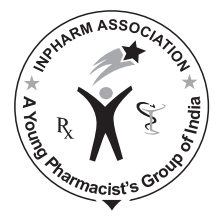

\title{
A Pilot Study to Evaluate Pharmaceutical Pictograms in a Multispecialty Hospital at Dehradun
}

\author{
Joshi Y, Kothiyal P1 \\ Himalayan Institute of Pharmacy \& Research, Rajawala, ${ }^{1}$ Faculty of Pharmacy, Dehradun Institute of \\ Technology, Dehradun (Uttarakhand), India
}

Address for correspondence: Mr. Yogesh Joshi; E-mail: yogeshjoshi1583@rediffmail.com

\begin{abstract}
Pharmaceutical pictograms have the potential to play an important role in optimizing compliance in the illiterate patient population. Pictograms may improve warning comprehension for those with visual or literacy difficulties and can sometimes be recognized and recalled far better than words. The main purpose of this study is to determine whether these pictograms can be effectively understood by illiterate patients, who otherwise cannot read the instructions given on their prescription order. In this study, 10 pharmaceutical pictograms were evaluated in patients attending the outpatient department of the Shri Mahant Indresh Hospital, a multispecialty, referral hospital in Dehradun (Uttarakhand). Understanding of pictograms by patients before and after interpretation was noted and follow-up interpretation was also noted. Results of the study showed that prior to explanation, the majority of the patients were unable to interpret the pictograms correctly but after explanation of their meaning, interpretation by them showed a marked improvement, indicating the need of using pictograms along with verbal reinforcement. The study also highlighted poor patient follow-up, a major cause of patient non-compliance, often leading to a poor therapeutic outcome of the prescribed medication order. Such problems can be taken care of by an active participation by healthcare professionals.
\end{abstract}

Key words: Illiterate, interpretation, patients, pictograms

\section{INTRODUCTION}

The term pictogram is a collective term used to describe both 'symbols' and 'pictorials'. Pictograms are standardized graphic images that help convey medication instructions, precautions, and/or warnings to patients and consumers.

\begin{tabular}{|l|l|}
\hline \multicolumn{2}{|c|}{ Access this article online } \\
\hline Quick Response Code: & \\
\hline & Website: \\
& www.jyoungpharm.in \\
& \\
\hline
\end{tabular}

Pictograms are particularly helpful in passing on important information to patients with a lower level reading ability and for whom English is a second language. ${ }^{[1]}$ Pharmaceutical pictograms have been designed to help people understand how to take their prescription medication. These are considered to be part of a universal language and can be easily recognized by all as they convey their meaning with little or no dependence on language or cultural background. Pictograms may improve warning comprehension for those with visual or literacy difficulties and can sometimes be recognized and recalled far better than words. ${ }^{[2]}$ They have the potential to be interpreted more accurately and more quickly than words. It was shown that the presence of pictograms contributed positively to both 
understanding of instructions and adherence. ${ }^{[3]}$ The success of using pictograms as a communication aid depends on a comprehensive design and testing process in order to produce clear, culturally acceptable pictograms, after which their value depends largely on their appropriate use by the healthcare professional who must provide verbal reinforcement in conjunction with the pictograms. ${ }^{[4,5]}$

\section{METHODOLOGY}

The study was conducted at the outpatient department, Shri Mahant Indresh Hospital, a 300-bed multispecialty, referral hospital in Dehradun (Uttarakhand). A total of 200 patients agreed to participate in this study. All the patients chosen for the study were illiterate. Ten pharmaceutical pictograms were randomly selected for the study. Nine of these pictograms were sourced from the United States Pharmacopoeia Dispensing Information (USP-DI) ${ }^{[6]}$ and the tenth pictogram was consciously selected keeping in mind the prevalence of asthma in Dehradun and poor usage of inhalers in such a population. Selected pharmaceutical pictograms were numbered from 1 to 10 and were given to the patients one by one to interpret their meaning. These 10 pictograms along with their meanings are shown in Figure 1. At the onset, patients were explained about the purpose of the study and invited to participate in it. The demographic details of the patients like name, gender, age, occupation and salary status were collected. Patients attending the outpatient department of the hospital were interviewed before and after explanation of the meaning of all 10 pictograms, and correct interpretation in percentage of pictograms was calculated accordingly. Follow-up interview of the patients was again planned according to their follow-up schedule in the prescription. Poor followup by the patients resulted in only 164 patients reporting back for an interview. Interpretation in percentage was calculated for these 164 patients.

\section{RESULTS}

The demographic details of the patients, viz. age, sex, occupation and salary are given in Table 1 . There were $84(42 \%)$ males and 116 (58\%) females in our study [Figure 2]. The age-wise distribution of patients shows that the majority of the patients $(31 \%)$ were between 40 49 years of age [Figure 3]. Occupation-wise distribution of patients showed that the majority of the patients $(42 \%)$ were housewives [Figure 4]. Salary-wise distribution of patients showed that the majority of the patients (58\%) were having no income [Figure 5]. Interpretation of pictograms before and after explanation as well as in the
Table 1: Demographic details of the patients

\begin{tabular}{lc}
\hline Distribution status & Number (\%) \\
\hline Gender & \\
Male & $84(42.00)$ \\
Female & $116(58.00)$ \\
Age (in years) & \\
$<20$ & $06(03.00)$ \\
$20-29$ & $27(13.50)$ \\
$30-39$ & $46(23.00)$ \\
$40-49$ & $62(31.00)$ \\
$50-59$ & $37(18.50)$ \\
$>60$ & $22(11.00)$ \\
Occupation & \\
Housewife & $84(42.00)$ \\
Service & $20(10.00)$ \\
Self-employed & $37(18.50)$ \\
Unemployed & $59(29.50)$ \\
Salary (in Rs.) & \\
No income & $116(58.00)$ \\
$<2000$ & $58(29.00)$ \\
$2000-5999$ & $12(06.00)$ \\
$6000-9999$ & $10(05.00)$ \\
$>10,000$ & $04(02.00)$ \\
\hline
\end{tabular}

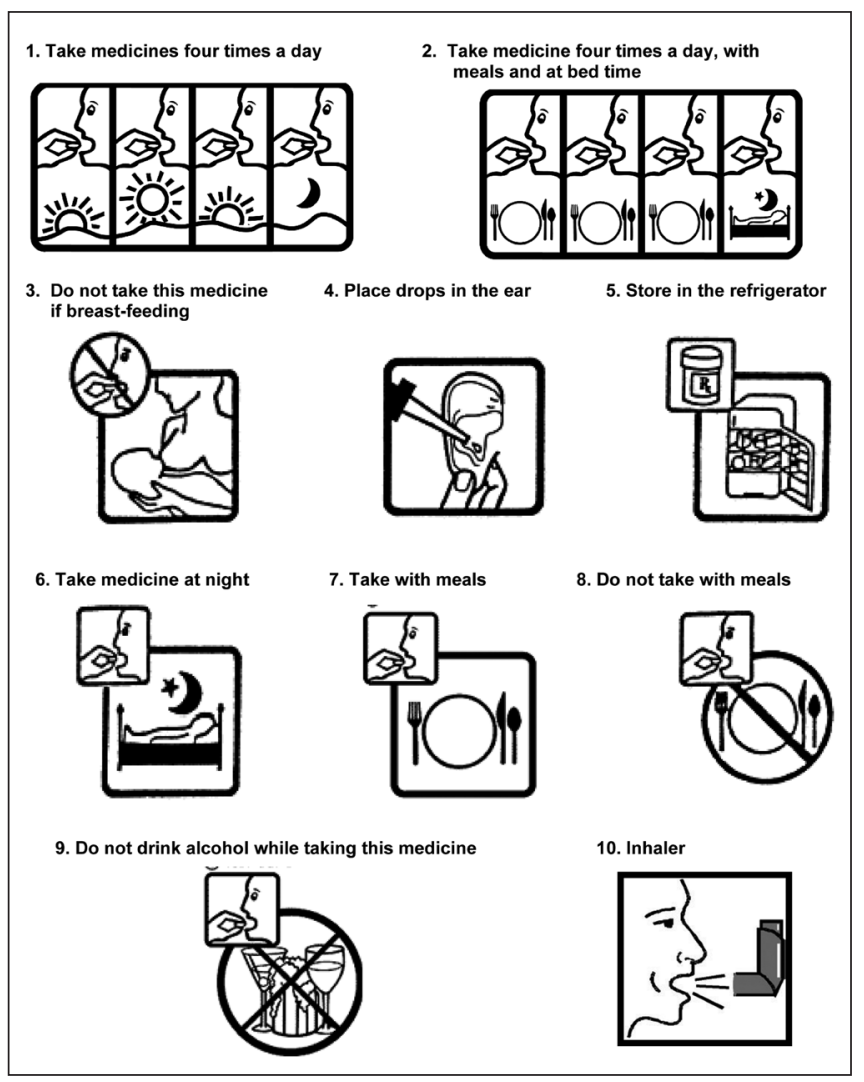

Figure 1: Pharmaceutical pictograms

follow-up interview is depicted in Table 2 [Figure 6]. Before explaining the meaning of pictograms, the majority of the patients were unable to interpret them correctly but after explanation, interpretation shown by them comparatively 


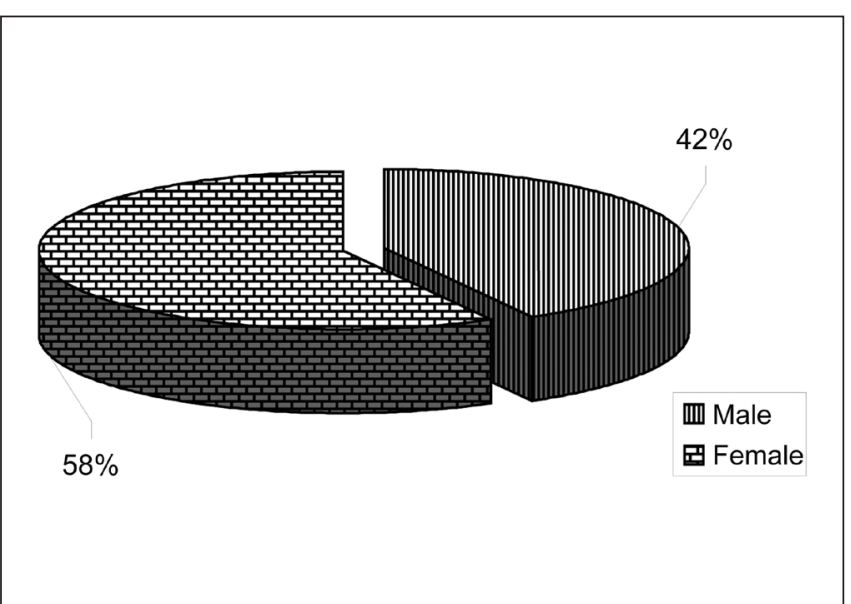

Figure 2: Gender-wise distribution of patients

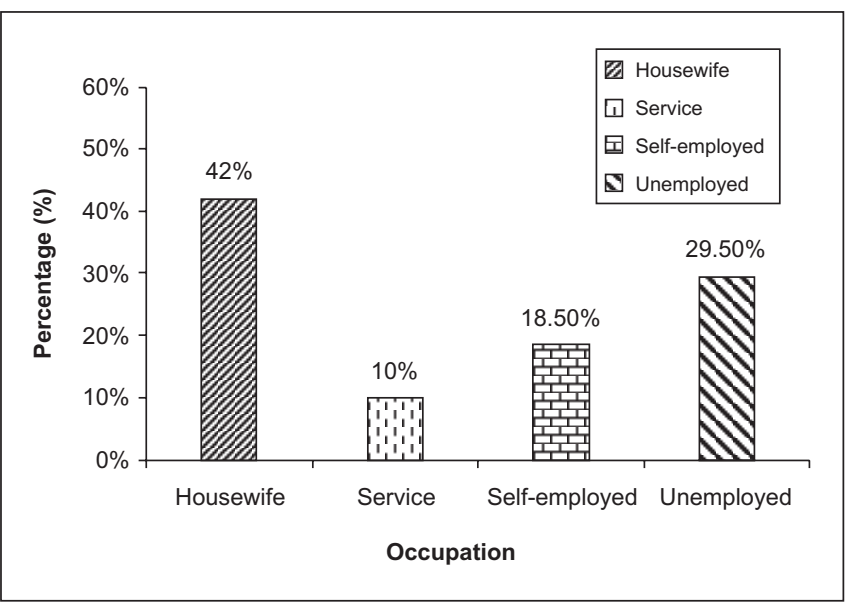

Figure 4: Occupation-wise distribution of patients

Table 2: Correct interpretation of pictograms before and after explanation

\begin{tabular}{|c|c|c|c|}
\hline \multirow{2}{*}{$\begin{array}{l}\text { Pictogram } \\
\text { No. }\end{array}$} & \multicolumn{2}{|c|}{ First interview } & \multirow{2}{*}{$\begin{array}{c}\text { Follow-up } \\
\text { interview (out of } \\
164 \text { follow-ups) } \\
\end{array}$} \\
\hline & $\begin{array}{c}\text { Before } \\
\text { explanation }\end{array}$ & $\begin{array}{c}\text { After } \\
\text { explanation }\end{array}$ & \\
\hline 1 & $45(22.50)$ & $155(77.50)$ & $110(67.07)$ \\
\hline 2 & $52(26.00)$ & $164(82.00)$ & $126(76.83)$ \\
\hline 3 & $121(60.50)$ & $177(88.50)$ & $138(84.15)$ \\
\hline 4 & $128(64.00)$ & $170(85.00)$ & $144(87.81)$ \\
\hline 5 & $130(65.00)$ & $155(77.50)$ & $140(85.37)$ \\
\hline 6 & $53(26.50)$ & $106(53.00)$ & $106(64.64)$ \\
\hline 7 & $77(38.50)$ & $105(52.50)$ & $104(63.42)$ \\
\hline 8 & $82(41.00)$ & $120(60.00)$ & $112(68.29)$ \\
\hline 9 & $95(47.50)$ & $127(63.50)$ & $124(75.61)$ \\
\hline 10 & $24(12.00)$ & $114(57.00)$ & $56(34.15)$ \\
\hline
\end{tabular}

Value in parentheses indicates percentage $(\%)$

improved. Prior to explanation, only 1\% patients correctly interpreted the meaning of all 10 pictograms whereas after explanation $9.5 \%$ patients managed to interpret the

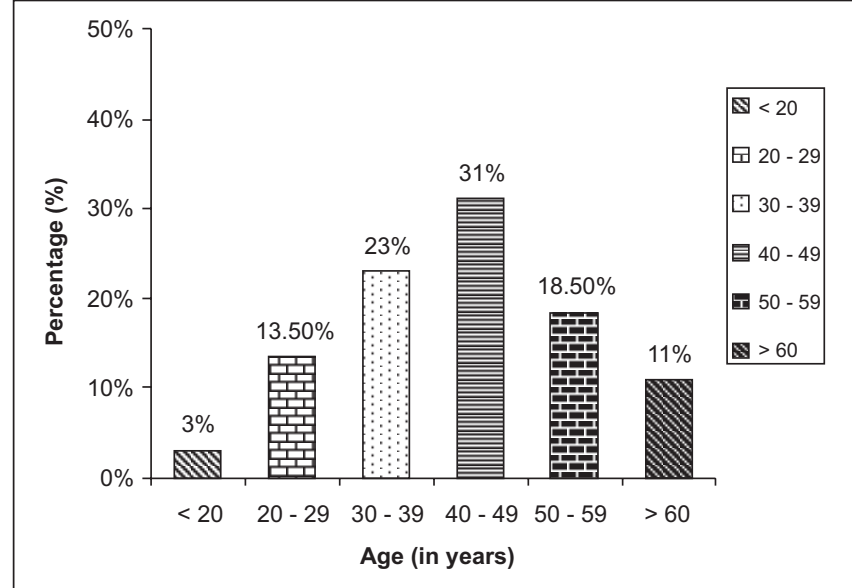

Figure 3: Age-wise distribution of patients

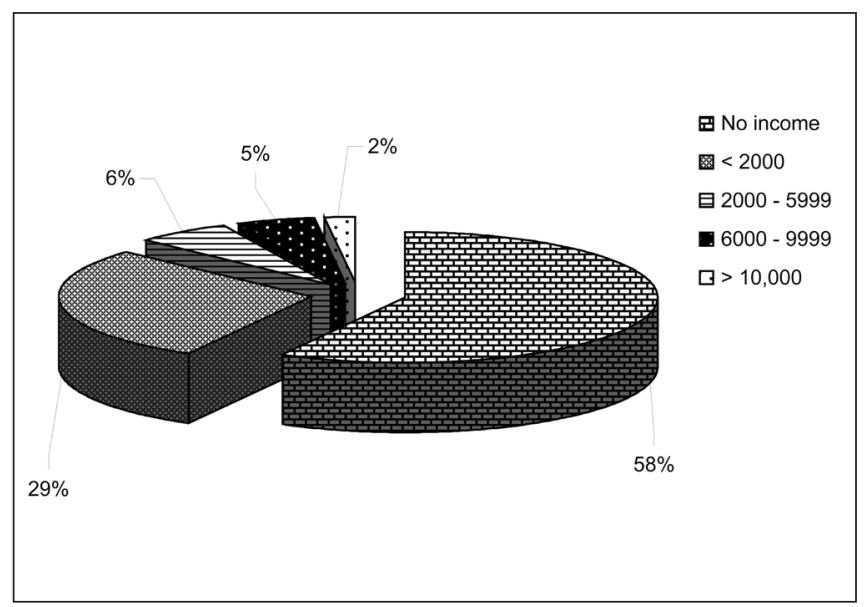

Figure 5: Salary-wise distribution of patients

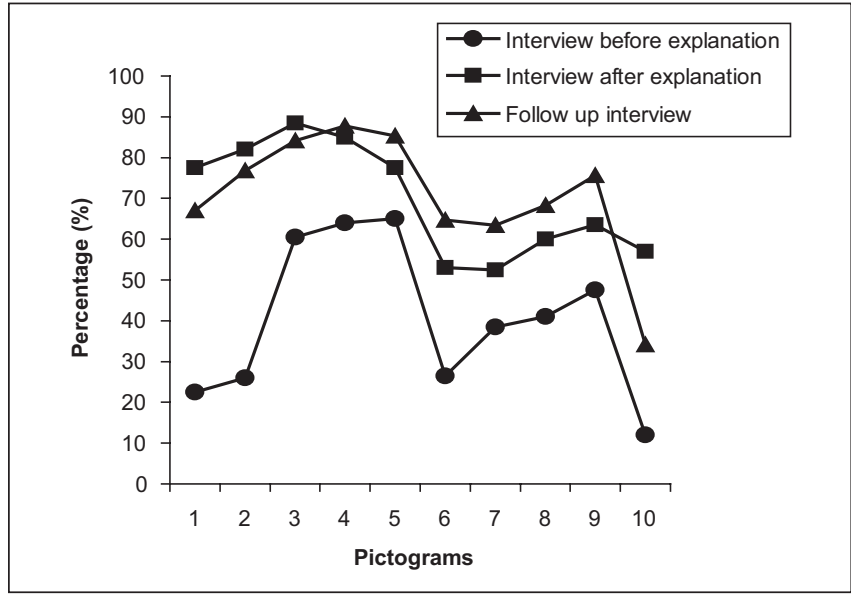

Figure 6: Comparison of interpretation of pictograms

meaning of all 10 pictograms. In the follow-up study, only $7.93 \%$ patients correctly interpreted the meaning of all 10 pictograms. Explanation comparatively improved the 
interpretation made by patients from $1 \%$ to $9.5 \%$ for all 10 pictograms. The most widely understood pictograms were - Take medicines four times a day, Place drops in the ear, Take medicine at night, Store in the refrigerator, Do not drink alcohol while taking this medicine and Do not take this medicine if breastfeeding.

\section{DISCUSSION}

Illiterate patients cannot read the details in prescriptions, labels, leaflets and thus cannot remember instructions. Research has shown that the pharmaceutical pictograms were valuable if used in an appropriate manner, i.e. in combination with verbal and written reinforcement. ${ }^{[7,8]} \mathrm{We}$, thus, evaluated selected pharmaceutical pictograms in the illiterate patient population of Dehradun. The majority of the patients were unable to interpret the meaning of pictograms correctly before explanation of their meaning but after explanation, interpretation of the meaning of pictograms comparatively improved. Only $1 \%$ patients correctly interpreted the meaning of all 10 pictograms prior to explanation whereas $9.5 \%$ patients managed to interpret the meaning of all 10 pictograms after the explanation of their meaning. Only $7.93 \%$ patients correctly interpreted the meaning of all 10 pictograms in the follow-up study and such poor patient follow-up during the study shows patient non-compliance, behavior which may ultimately affect the therapeutic outcome in them. Demographic information that showed the socioeconomic status of the study population included the key factors responsible for the outcomes of the study. The major emphasis to improve these limitations could be possible only by improving the literacy in such population.

\section{CONCLUSION}

Prior explanation is required for proper recall of medication use instructions. Pictograms need to be developed for such illiterate patient population and the problem of patient non-compliance can be solved by the active participation by every healthcare professional with hand in hand cooperation by patients. However, it was felt that the pictograms need to be more culture-specific and can be reinforced with information, so as to cater to people of low socioeconomic strata. This would greatly enhance the patients' understanding of the medication order and thus lead to improved compliance.

\section{REFERENCES}

1. United States Pharmacopoeia Dispensing Information. Vol. 2. $20^{\text {th }}$ ed. NJ: Micromedex, Inc., Englewood; 2000. p. 1617-26.

2. Dowse R, Ehlers MS. Pictograms for conveying medicine instructions: comprehension in various South African language groups. S Afr J Sci 2004;100:687-93.

3. Dowse R, Ehlers MS. Medicine labels incorporating pictograms: do they influence understanding and adherence? Patient Educ Couns 2005;58:63-70.

4. Dowse R, Ehlers MS. The evaluation of pharmaceutical pictograms in a low literate South African population. Patient Educ Couns 2001;45:87-99.

5. Dowse R, Ehlers MS. Pictograms in pharmacy. Int J Pharm Pract 1998;6:109-18.

6. U.S. Pharmacopeia. USP pictograms. Available from: http://www.usp.org/ audiences/consumers/ pictograms/form.html. [last cited on 2010 Jun 20].

7. Dowse R, Ehlers MS. Pharmaceutical Pictograms. Part 2. Weird and wonderful interpretations. S Afr Pharm J 2003;70:42-5.

8. How pictograms can reinforce patient information. Pharm J 1999;263:612 Available from: http://www.pharmj.com/editorial/19991009/forum/ pictograms.html. [last cited on 2010 Jun 20].

Cite this article as: Joshi Y, Kothiyal P. A pilot study to evaluate pharmaceutical pictograms in a multispecialty hospital at Dehradun. $J$ Young Pharmacists 2011;3:163-6.

Source of Support: Nil, Conflict of Interest: None declared.

\section{Staying in touch with the journal}

1) Table of Contents (TOC) email alert

Receive an email alert containing the TOC when a new complete issue of the journal is made available online. To register for TOC alerts go to http://www.jyoungpharm.in/signup.asp.

\section{2) RSS feeds}

Really Simple Syndication (RSS) helps you to get alerts on new publication right on your desktop without going to the journal's website. You need a software (e.g. RSSReader, Feed Demon, FeedReader, My Yahoo!, NewsGator and NewzCrawler) to get advantage of this tool. RSS feeds can also be read through FireFox or Microsoft Outlook 2007. Once any of these small (and mostly free) software is installed, add http://www.jyoungpharm.in/rssfeed.asp as one of the feeds. 